\title{
Long-term Creep Properties of Cementitious Materials: Comparing Microindentation Testing with Macroscopic Uniaxial Compressive Testing
}

\author{
Qing Zhanga,b, Robert Le Roy ${ }^{\mathrm{a}}$, Matthieu Vandamme ${ }^{\mathrm{a}}$, Bruno Zuber ${ }^{\mathrm{b}}$ \\ ${ }^{a}$ Université Paris-Est, Laboratoire Navier (École des Ponts ParisTech, IFSTTAR, \\ CNRS) 6-8 Av. B. Pascal, 77420 Champs-sur-Marne, France \\ ${ }^{b}$ Lafarge centre de recherche, 95 rue du Montmurier, BP 1538291 St Quentin Fallavier \\ Cedex, France
}

\section{Abstract}

This study is dedicated to comparing minutes-long microindentation creep experiments on cement paste with years-long macroscopic creep experiments on concrete and months-long macroscopic creep experiments on cement paste. For all experiments, after a transient period the creep function was well captured by a logarithmic function of time, the amplitude of which is governed by a so-called creep modulus. The non-logarithmic transient periods lasted for days at the macroscopic scale, but only for seconds at the scale of microindentation. The creep moduli (which thus govern the rate of the long-term logarithmic creep) of concrete samples were estimated from microindentations performed at the scale of cement pastes in combination with micromechanical models. Those estimates were proportional to the creep moduli measured on concrete samples by regular macroscopic uniaxial testing, thus proving that minutes-long microindentation can provide a measurement of the long-term creep properties of cementitious materials.

Keywords: Creep, Long-Term Performance, Mechanical Properties 


\section{Introduction}

In concrete, a variety of phenomena can lead to deformations that evolve over time: autogenous shrinkage, drying shrinkage, aging... Out of this variety, one phenomenon is basic creep, which is defined as the time-dependent deformation that is only due to the application of an external mechanical load. In this study, we focus on this basic creep (samples were sealed to prevent any desiccation). Creep of concrete is usually divided into at least two distinct kinetics [4]: a short-term creep, followed by a deviatoric long-term creep.

Indeed, concrete creeps, i.e., slowly deforms over time when subjected to constant stress. Both short term and long term creep are important for the stability, durability, and serviceability of concrete structure. The importance of taking creep deformation into consideration in the design of concrete structures was recalled recently [3]. The deformation due to creep evolves over years or even over decades. Therefore, in order to get a reliable prediction of the long-term creep deformations of concrete, various authors recommend for creep experiments on concrete to last for at least several months [15, 16]. The long duration of those experiments makes it not only time-consuming but also difficult to characterize creep properties. Indeed, over those long periods of time, experimental parameters must be very well controlled: for instance, the load has to remain constant, temperature must not vary and hydric exchanges with the surroundings must be prevented. In addition, since other physical phenomena can lead to time-dependent deformations of the concrete samples, basic creep is usually measured by performing two experiments in parallel [16]: deformations due to basic creep are calculated as the difference 
between the time-dependent deformation of a sealed sample under load and the time-dependent deformation of another sealed sample without external load (autogenous shrinkage). This need to run two experiments in parallel increases experimental uncertainties, so that a dispersion of about $16.5 \%$ on long-term creep results on concrete samples loaded at 28 days can eventually be expected [5]. For samples loaded at an early age, this dispersion is rather on the order of $20 \%$ [5].

The creep of concrete is mainly due to the creep of cement paste [12]. For Portland cement, its creep behavior is mainly determined by its porosity and the creep properties of C-S-H (i.e., of calcium silicate hydrates). In order to measure mechanical properties of individual phases of heterogeneous materials, the indentation technique proves to be well-suited $[6,7,30,36$, 20, 21]. The possibility to measure viscous properties by indentation in particular has been shown on polymers [23, 18], metals [27], cementitious materials $[33,8,34,24]$, and so on. Therefore, in order to predict the creep behavior of concrete, one could think of characterizing the creep behavior of cement paste, or of C-S-H, and upscale this behavior to the scale of concrete samples. Vandamme and Ulm showed that the long-term kinetics of concrete can indeed be quantitatively estimated from a grid of nanoindentation tests performed at the sub-micrometer scale of the C-S-H phases [34].

In the present work, we aim at verifying whether an estimation of the macroscopic creep behavior of concrete samples can be inferred from microindentation tests performed at the scale of the cement paste. With this objective, we compared minutes-long microindentation creep experiments on cement paste samples with months-long macroscopic uniaxial creep experi- 
ments on cement paste samples and years-long macroscopic uniaxial creep experiments on concrete samples. The next section is dedicated to describing the materials and methods. Results are then presented and discussed, before conclusions are drawn.

\section{Materials and methods}

Both cement samples and concrete samples were prepared. On the concrete samples, years-long macroscopic uniaxial creep experiments were performed. On the cement samples, both months-long macroscopic uniaxial creep experiments and minutes-long microindentation creep experiments were performed.

\subsection{Materials}

All cement paste samples and concrete samples were made with Portland cement (class CEM I 52.5). Both clinkers from Saint Vigor (Lafarge, France) and from Saint-Pierre-la-Cour (Lafarge, France) were used, which contain different amounts of tricalcium aluminate (see Table 1). Concrete samples and cement samples for uniaxial creep testing were manufactured in 1992, while cement samples for microindentation creep testing were manufactured in 2011. Clinkers from Saint Vigor used in 1992 and in 2011 were from the same factory, as was the case for clinkers from Saint-Pierre-la-Cour. The composition of the clinkers used in the various samples is provided in Table 1, while their physical properties are provided in Table 2. Although the clinkers used in the samples for uniaxial testing and for microindentation testing were manufactured about 20 years apart, the composition and the specific gravity of the two batches differed very little from each other. The 


\begin{tabular}{c|c||cccccc}
\hline & Year & $\mathrm{CaO}$ & $\mathrm{SiO}_{2}$ & $\mathrm{Al}_{2} \mathrm{O}_{3}$ & $\mathrm{Fe}_{2} \mathrm{O}_{3}$ & $\mathrm{SO}_{3}$ & $\mathrm{LOI}^{(a)}$ \\
\hline \hline \multirow{2}{*}{$\begin{array}{c}\text { Cement from } \\
\text { Saint Vigor }\end{array}$} & 1992 & 64.25 & 22.49 & 3.60 & 4.00 & 2.50 & 1.48 \\
\cline { 2 - 8 } & 2011 & 64.76 & 20.87 & 3.58 & 4.45 & 2.45 & 1.06 \\
\hline \hline $\begin{array}{c}\text { Cement from } \\
\text { Saint-Pierre-la-Cour }\end{array}$ & 1992 & 65.30 & 19.72 & 4.98 & 2.71 & 3.36 & 1.30 \\
\cline { 2 - 8 } & 2011 & 63.94 & 20.06 & 4.93 & 2.86 & 3.67 & 1.45 \\
\hline \hline \multirow{2}{*}{$\begin{array}{c}\text { Silica fume } \\
\text { from Laudun }\end{array}$} & 1992 & - & 87.00 & - & - & - & 3.09 \\
\cline { 2 - 7 } & 2011 & - & 93.31 & - & - & - & 3.43 \\
\hline
\end{tabular}

Table 1: Mass percentage of chemical components in the clinkers and silica fume used in this study. Data is provided by the manufacturer (Lafarge). For clinker and silica fume, respectively, only mass percentages greater than $1 \%$ and than $3 \%$ are given.

(a) LOI: loss on ignition.

proportion of the main phases in the clinkers used to prepare cement pastes for microindentation testing is given in Table 3 .

In some samples, silica fume was used as an additive. Both silica fume used in 1992 and in 2011 were from Laudun (France). As can be observed in Table 1, from one set to the other the content of $\mathrm{SiO}_{2}$ varied by about $6 \%$. And Table 2 shows that the specific gravity of the silica fume used in 2011 was about $20 \%$ greater than that of the silica fume used in 1992. To some samples a superplasticizer was added (see Table 4), the solid content of which was $30.5 \%$ and the effective component of which was melamine.

The mix formulation of the various samples used in this study is given in Table 4. Cylindrical concrete samples were prepared in 1992 with seven various mix formulations. For each formulation, four samples were dedicated to uniaxial strength testing (the diameter of these samples was $110 \mathrm{~mm}$ and their height was $220 \mathrm{~mm}$ ), one sample was dedicated to autogenous shrinkage testing (the diameter of this sample was $160 \mathrm{~mm}$ and its height was $1000 \mathrm{~mm}$ ), 


\begin{tabular}{c|c||c|c}
\hline & Year & $\begin{array}{c}\text { Specific } \\
\text { surface }\left(\mathrm{m}^{2} \cdot \mathrm{g}^{-1}\right)\end{array}$ & $\begin{array}{c}\text { Specific } \\
\text { gravity }\left(\mathrm{g} \cdot \mathrm{cm}^{-3}\right)\end{array}$ \\
\hline \hline \multirow{2}{*}{$\begin{array}{c}\text { Cement from } \\
\text { Saint Vigor }\end{array}$} & 1992 & 0.35 & 3.17 \\
\cline { 2 - 4 } & 2011 & 0.35 & 3.18 \\
\hline \hline $\begin{array}{c}\text { Cement from } \\
\text { Saint-Pierre-la-Cour }\end{array}$ & 1992 & - & - \\
\cline { 2 - 4 } & 2011 & 0.45 & 3.11 \\
\hline \hline \multirow{2}{\text{Silicafume}}{ from Laudun } & 1992 & 17.6 & 2.20 \\
\cline { 2 - 4 } & 2011 & 21.3 & - \\
\hline
\end{tabular}

Table 2: Physical properties of clinker and silica fume used in this study. Data is provided by the manufacturer (Lafarge).

\begin{tabular}{l||ccccc}
\hline Cement & $\mathrm{C}_{3} \mathrm{~S}$ & $\mathrm{C}_{2} \mathrm{~S}$ & $\mathrm{C}_{3} \mathrm{~A}$ & $\mathrm{C}_{4} \mathrm{AF}$ & gypsum \\
\hline \hline Saint Vigor (2011) & 60.0 & 22.4 & 1.20 & 12.9 & 1.30 \\
Saint-Pierre-la-Cour (2011) & 59.9 & 17.6 & 7.40 & 9.40 & 0.30 \\
\hline
\end{tabular}

Table 3: Proportion of the main phases in the clinkers used in 2011 to prepare cement paste samples for microindentation testing, determined by Rietveld X-ray diffraction quantification. Data is provided by the manufacturer (Lafarge). 
and the last sample was dedicated to uniaxial creep testing the geometry of this sample was the same as that of the sample dedicated to autogenous shrinkage). The mix formulations of those concretes differed by the waterto-cement ratio $w / c$, the mass ratio $s / c$ of silica fume to clinker, and the volume fraction of aggregates (i.e., of sand and gravel).

Six groups of cylindrical cement paste samples were prepared in 1992 with a diameter equal to $20 \mathrm{~mm}$ and a height equal to $160 \mathrm{~mm}$. For each group, two samples were prepared: one was used for autogenous shrinkage test and the other one for uniaxial creep test. The mix formulations of those pastes differed by the water-to-cement ratio $w / c$, the mass ratio $s / c$ of silica fume to clinker, and the type of clinker used (from Saint Vigor or from Saint-Pierre-la-Cour). Samples with identical mix formulations and geometry were prepared again in 2011 for microindentation creep test. In addition, the cement paste P33-1SV (see Table 4 for sample designation) was also prepared for microindentation testing, although paste with this mix formulation was not tested by uniaxial test: by doing so, all cement pastes used in both cement pastes and concretes in 1992 were manufactured again in 2011 for microindentation test.

Samples were prepared according to the following procedure. For cement paste samples the mixing consisted in: adding the solid raw materials, the water, and one third of the superplasticizer; mixing for 3 minutes; adding the rest of superplasticizer; mixing for 2 minutes. For concrete samples the mixing consisted in: adding the solid raw materials; mixing for 1 minute; adding water and one third of the superplasticizer; mixing for 2 minutes; adding the rest of the superplasticizer; mixing for 1 minute. After molding, 


\begin{tabular}{l||llllll||cc}
\hline Sample & Cement & $w / c^{(a)}$ & $s / c^{(b)}$ & $p / c^{(c)}$ & $f_{a g g}^{(d)}(\%)$ & $1992^{(e)}$ & $2011^{(f)}$ \\
\hline \hline P28-0SV & Saint Vigor & 0.28 & 0.0 & $1.5 \%$ & - & $\mathrm{X}$ & $\mathrm{X}$ \\
\hline P38-0SV & Saint Vigor & 0.38 & 0.0 & $0.0 \%$ & - & $\mathrm{X}$ & $\mathrm{X}$ \\
\hline P50-0SV & Saint Vigor & 0.50 & 0.0 & $0.0 \%$ & - & $\mathrm{X}$ & $\mathrm{X}$ \\
\hline P28-1SV & Saint Vigor & 0.28 & 0.1 & $1.5 \%$ & - & $\mathrm{X}$ & $\mathrm{X}$ \\
\hline P33-1SV & Saint Vigor & 0.33 & 0.1 & $1.5 \%$ & - & & $\mathrm{X}$ \\
\hline P38-1SV & Saint Vigor & 0.38 & 0.1 & $1.5 \%$ & - & $\mathrm{X}$ & $\mathrm{X}$ \\
\hline P38-0LC & Saint-Pierre & & & & & & \\
\hline \hline B28-1 & -la-Cour & 0.38 & 0.0 & 1.5 & - & $\mathrm{X}$ & $\mathrm{X}$ \\
\hline B38-1 & Saint Vigor & 0.28 & 0.1 & $4.7 \%$ & 71.0 & $\mathrm{X}$ & \\
\hline B50-0 & Saint Vigor & 0.38 & 0.1 & $4.9 \%$ & 71.3 & $\mathrm{X}$ & \\
\hline B33-1A & Saint Vigor & 0.50 & 0.0 & $0.0 \%$ & 70.5 & $\mathrm{X}$ & \\
\hline B33-1B & Saint Vigor & 0.33 & 0.1 & $4.9 \%$ & 67.3 & $\mathrm{X}$ & \\
\hline B33-1C & Saint Vigor & 0.33 & 0.1 & $4.8 \%$ & 71.5 & $\mathrm{X}$ & \\
\hline B33-1D & Saint Vigor & 0.33 & 0.1 & $4.9 \%$ & 73.1 & $\mathrm{X}$ & \\
\hline
\end{tabular}

Table 4: Mix formulations of cement paste samples (the denomination of which starts with the letter P) and concrete samples (the denomination of which starts with the letter B) prepared in this study.

(a) $w / c$ denotes the water-to-cement mass ratio; (b) $s / c$ stands for the mass ratio of silica fume to clinker; (c) $p / c$ denotes the superplasticizer to cement ratio; (d) $f_{\text {agg }}$ denotes the volume fraction of aggregates (i.e., gravel and sand) in concrete; (e) samples prepared in 1992 were used for uniaxial creep experiments; (f) samples prepared in 2011 were used for microindentation creep experiments. 
for both cement paste samples and concrete samples, embedded gas bubbles were evacuated by vibration on a vibration table; samples were unmolded 24 hours after mixing and enveloped in 2 layers of self-sealing aluminum paper; samples were conserved at $20^{\circ} \mathrm{C} \pm 1^{\circ} \mathrm{C}$ and at a relative humidity $50 \% \pm 5 \%$ till testing. For cement paste only, right after vibration the samples were rotated for 15 hours in order to prevent any segregation.

\subsection{Years-long uniaxial compression creep experiments on concrete}

On the concrete samples, basic creep was measured up to 15 years. This basic creep was obtained by performing in parallel autogenous shrinkage test on one sample and creep test on another sample with identical mix formulation and geometry. The autogenous shrinkage test started 24 hours after casting. During this test, no load was applied to the sample and the axial strain $\epsilon_{s}(t)$ was measured over time. On the samples to be loaded for the creep experiments by uniaxial compression, we also started measuring a total axial strain $\epsilon_{t}(t) 24$ hours after casting. On these samples, the application of a uniaxial compression started 28 days after casting. During the creep periods, a uniaxial compressive stress $\sigma_{u}$ equal to $30 \%$ of the 28-day uniaxial compression strength was applied and kept constant, and we kept measuring the axial strain $\epsilon_{t}(t)$ over time. The reference time $t=0$ corresponds to the time at which the load was applied for the creep experiments, i.e., to 28 days after casting. The compression strength was obtained on a distinct sample with the same mix formulation and the same geometry just before the commencement of the creep test, by following the then-used French standard NFP 18-406. The duration of the tests varied from 150 days to 5230 days (i.e., about 14.5 years) for the various samples. All tests were performed in 
sealed conditions at $20^{\circ} \mathrm{C} \pm 2^{\circ} \mathrm{C}$.

For a linear viscoelastic sample subjected to a known uniaxial stress $\sigma_{u}(t)$ applied over positive time $t>0$, the resulting uniaxial strain $\epsilon_{u}(t)$ can be calculated through the uniaxial creep compliance $J_{u}(t)$ with [26]:

$$
\epsilon_{u}(t)=\int_{0}^{t} J_{u}(t-\tau) \dot{\sigma_{u}}(\tau) d \tau
$$

where $\dot{f}$ stands for the time derivative of a function $f$. At time $t=0$, the uniaxial creep compliance must be equal to: $J_{u}(t=0)=1 / E_{0}$, where $E_{0}$ is the elastic Young's modulus of the material. The function $J_{u}(t)-J_{u}(0)=$ $J_{u}(t)-1 / E_{0}$ is known as the uniaxial creep function.

For mature concrete subjected to negligible variations of temperatures, linear viscoelasticity is expected to apply reasonably well, as long as the applied stresses increase or slightly decrease over time [13]. For such materials, which can also be subjected to drying-induced shrinkage or autogenous shrinkage, the correct strain to consider in Eq. (1) is the so-called basic creep strain $\epsilon_{b}(t)$. From the uniaxial experiments here performed on concrete samples, this basic creep strain $\epsilon_{b}(t)$ was obtained as the difference between the total axial strain $\epsilon_{t}(t)$ measured on the concrete sample under load and the axial strain $\epsilon_{s}(t)$ due to autogenous shrinkage and measured on the concrete sample subjected to no load: $\epsilon_{b}(t)=\epsilon_{t}(t)-\epsilon_{s}(t)$. Since the load was kept constant over time during the macroscopic creep experiments, a direct use of Eq. (1) shows that the uniaxial basic creep compliance $J_{u}(t)$ of the concrete samples could be obtained with the following formula:

$$
J_{u}(t)=\frac{\epsilon_{b}(t)}{\sigma_{u}}=\frac{\epsilon_{t}(t)-\epsilon_{s}(t)}{\sigma_{u}}
$$


We recall that the function $J_{u}(t)-J_{u}(0)=J_{u}(t)-1 / E_{0}$ is the uniaxial creep function. The creep experiments started 28 days after casting, so that we neglected the aging feature of the viscous behavior. The reference time $t=0$ corresponds to the time at which the load was applied for the creep experiments. For concrete samples B28-1, B33-1A, B33-1B, and B33-1D, the shrinkage experiments were terminated between 1289 and 1338 days after loading. For these samples, subsequent autogenous shrinkage was estimated by extrapolating the experimental data with the function $\epsilon_{s}=\epsilon_{s}^{\infty}\left(t / t_{0}\right)^{a} /\left(\left(t / t_{0}\right)^{a}-b\right)$, in which $t_{0}=1$ day and the parameters $\epsilon_{s}^{\infty}, a$ and $b$ were fitted for each sample.

\subsection{Months-long uniaxial compression creep experiments on cement paste}

On the cement paste samples, basic creep was measured, again by performing in parallel an autogenous shrinkage test and a creep test on samples with identical mix formulation and geometry. Autogenous shrinkage experiments started 24 hours after mixing. Creep experiments under uniaxial compression started 28 days after casting. The axial stress applied on sample P50-0SV was $9.4 \mathrm{MPa}$ (i.e., about $28 \%$ of its compressive strength at 28 days after mixing). For all other cement paste samples, the applied stress was $15.6 \mathrm{MPa}$ (i.e., from about $13 \%$ to $22 \%$ of their compressive strengths at 28 days after mixing). The duration of the creep test was of about 100 days for all samples. All tests were performed in sealed conditions at $20^{\circ} \mathrm{C} \pm 2^{\circ} \mathrm{C}$.

The basic creep strain $\epsilon_{b}(t)$ was again obtained as the difference between the total axial strain $\epsilon_{t}(t)$ measured on the cement paste sample under load and the axial strain $\epsilon_{s}(t)$ due to autogenous shrinkage and measured on the cement paste sample subjected to no load: $\epsilon_{b}(t)=\epsilon_{t}(t)-\epsilon_{s}(t)$. From the 
measured basic creep strain, the uniaxial creep functions $J_{u}(t)$ of the various cement paste samples were obtained with Eq. (2). Here the reference time $t=0$ also corresponds to the time at which the load was applied for the creep experiments, i.e., to 28 days after casting.

\subsection{Minutes-long microindentation creep experiments on cement paste}

On the cement paste samples, we also aimed at performing indentation creep experiments, 28 days after casting. One day before testing, the samples were moved into the room in which the microindenter was located and the temperature was controlled at $23^{\circ} \mathrm{C}$. About five minutes before testing, a 10-millimeters-thick disk was cut from the median part of the cylindrical sample. The surface to be indented was then polished with 4 pads of silicon carbide (SiC) paper with decreasing particle size. Polishing lasted for about 3 minutes, without any contact with water or other solvents. With respect to the polishing procedure recommended by Miller et al. for nanoindentation testing of cementitious materials [19], the duration of the procedure we used here was much shorter. Indeed, since the scale of microindentation testing is much larger than that of nanoindentation testing, our requirements on surface roughness were much less strict than for those authors. In addition, a rapid procedure also allowed to minimize drying. A typical surface with a typical indent is presented in Fig. 1. As can be observed, the scale of the indent is greater than the characteristic scale of the microstructure of the cement paste: thus, the performed microindentation tests provided the mechanical properties of the cement paste itself (and not of the individual phases of which this cement paste is constituted).

The microindenter was calibrated according to the ASTM standard E 


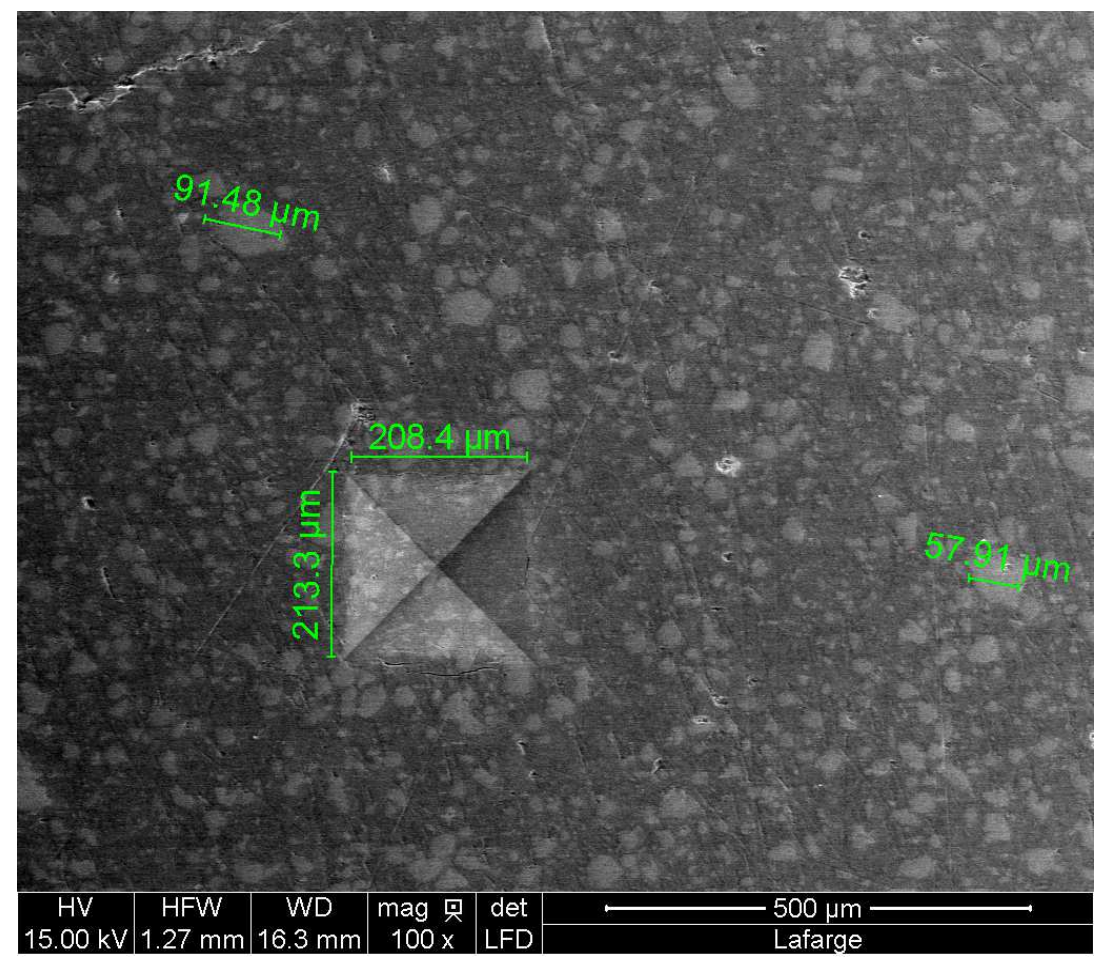

Figure 1: Scanning electron microscopy picture of the surface of an indented cement sample. 
2546-07 [1]. On each sample, 10 microindentation tests were performed with a Vickers indenter probe and a maximal applied force of 20 N. For each indent, the load was increased linearly over time in 15 seconds, kept constant during the holding phase, and decreased linearly over time back to zero in 15 seconds. Out of the 10 indents performed on each sample, 5 were with a relatively short 20-seconds-long holding phase, while 5 were performed with a relatively long 300-seconds-long holding phase. Indents with a 20-secondslong holding phase enabled to measure the indentation modulus $M_{0}$ of the paste by following the ASTM standard E 2546-07 [1], which employs the Oliver and Pharr method [22]. The indentation modulus $M_{0}$ of the indented material is linked to its Young's modulus $E_{0}$ and Poisson's ratio $\nu_{0}$ through [10]:

$$
M_{0}=\frac{E_{0}}{1-\nu_{0}^{2}}
$$

When reported in this work, the indentation modulus $M_{0}$ of a paste was obtained by averaging the 5 indentation moduli obtained from the 5 microindentation tests with a 20-seconds-long holding phase.

Indents with a 300-seconds-long holding phase enabled to measure the creep properties of the paste. For a linear viscoelastic material, upon indentation by a conical probe, the load $P(t)$ can theoretically be linked to the indentation depth $h(t)$ and its evolutions over time through the use of a so-called contact creep compliance $L(t)$ with [31]:

$$
h^{2}(t)=\frac{\pi}{2 \tan (\theta)} \int_{0}^{t} L(t-\tau) \dot{P}(\tau) d \tau
$$

where $\theta$ is the semi-apex angle of the conical probe. For the Vickers indenta- 
tions performed in this study, the semi-apex angle of the equivalent conical probe is $\theta=70.32^{\circ}$. The introduced contact creep compliance $L(t)$ has been shown to be a material property, i.e., a function that depends neither on the geometry of the probe, nor on the load used for the creep experiment [31]. This contact creep compliance bears as much information on the viscoelastic properties of the material as the uniaxial creep compliance $J_{u}(t)$ introduced in Sec. 2.2. As was the case with the uniaxial creep compliance $J_{u}(t)$, the contact creep compliance $L(t)$ at time $t=0$ is fully determined by the elastic properties [31]: $L(t=0)=1 / M_{0}$.

However, upon conical indentation testing, Eq. (4) remains only theoretical. Because of the concentration of stresses at the tip of the indenter probe, the indented material is deformed plastically even at the lowest applied load. In spite of the occurrence of time-independent plasticity, the contact creep function $L(t)-L(0)$ can be back-calculated from the holding phase of a conical indentation creep experiment, as given by the following formula [31]:

$$
L(t)-L(0)=L(t)-\frac{1}{M_{0}}=\frac{2 a_{u} \Delta h(t)}{P_{\max }}
$$

where $P_{\max }$ is the applied load during the holding phase of the test, $\Delta h(t)$ is the increment of the penetration depth of the indenter probe with respect to the indented surface during holding and $a_{u}$ is the radius of the equivalent projected contact area between the indenter probe and the indented surface at the onset of unloading. The radius was estimated with the Oliver and Pharr method [22]. In the equation above, the reference time $t=0$ corresponds to the instance when the load applied to the indenter tip reaches the maximum value, i.e., to the beginning of the holding phase. At this reference 
time $t=0$, the contact creep compliance $L(t)$ must be equal to $L(0)=1 / M_{0}$. The indentation modulus $M_{0}$ could be measured from the unloading phase of the microindentation test performed with the 300-seconds-long holding phases: indeed, within the frame of linear viscoelasticity one can show that, if the holding phase is sufficiently long and the unloading phase sufficiently short, the indentation modulus measured with the Oliver and Pharr method is unbiased by viscous effects and thus truly representative of the instantaneous elastic properties of the indented material [9, 32]. However, in our work, we focus on the contact creep function $L(t)-L(0)$ rather than the contact creep compliance $L(t)$ and Eq. (5) shows that the back-calculation of such creep functions from microindentation creep experiments requires no determination of the elastic indentation modulus $M_{0}$.

On sample P38-0SV, one indentation creep experiment with a 1800seconds-long holding phase was also performed in order to determine the shape of the creep function at longer term. For this last experiment, the maximal load still was $20 \mathrm{~N}$, the duration of the loading phase $15 \mathrm{~s}$, and the duration of the unloading phase $15 \mathrm{~s}$.

The internal relative humidity of cement paste cured in sealed conditions at temperature of $20^{\circ} \mathrm{C}$ varies from $90 \%$ to $98 \%$ at the age of 28 days [14, 25]. Therefore, in order to avoid drying during testing, all microindentation creep experiments were performed in an environment with a relative humidity equal to $91 \% \pm 2 \%$ and temperature equal to $23^{\circ} \mathrm{C} \pm 0.2^{\circ} \mathrm{C}$. By doing so, we expect drying-induced strains to be negligible with respect to the strains induced by creep. Moreover, at the age of 28 days, the autogenous shrinkage of cement over the duration of the 300-seconds-long creep phase can be neglected with 
respect to the strains induced by creep. As a consequence, the contact creep compliance $L(t)$ is expected to characterize the basic creep of the cement paste.

\section{Results}

\subsection{Raw results}

Figure 2 displays the uniaxial basic creep functions $J_{u}(t)-1 / E_{0}$ of the cement paste samples obtained by uniaxial compression. In this figure, $t=0$ stands for the time at which loading was applied. For samples with no addition of silica fume, creep increased with the water-to-cement ratio $w / c$. For samples with $10 \%$ of silica fume added, varying the water-to-cement ratio $w / c$ from 0.28 to 0.38 hardly varied the amplitude of creep. For a given water-to-cement ratio (i.e., $w / c=0.28$ or $w / c=0.38$ ), adding $10 \%$ of silica fume decreased creep. For given mix proportions, changing the clinker (i.e., using a clinker from Saint Vigor (sample P38-0SV) or from Saint-Pierre-laCour (sample P38-0SL) slightly modified the creep of the paste: however, after a few days, the difference between the two basic creep functions mostly remained constant over time, which means that the difference between the creep of those two pastes was mostly due to the time-dependent behavior of the pastes during the first days of loading.

The basic creep functions of the concrete samples obtained by uniaxial compression are displayed in Fig. 3. In a consistent manner with the results obtained on cement pastes, this figure shows that basic creep of concrete increased with the water-to-cement ratio $w / c$. A comparison of the results for samples B33-1A, B33-1B, B33-1C, and B33-1D shows that, globally, creep 


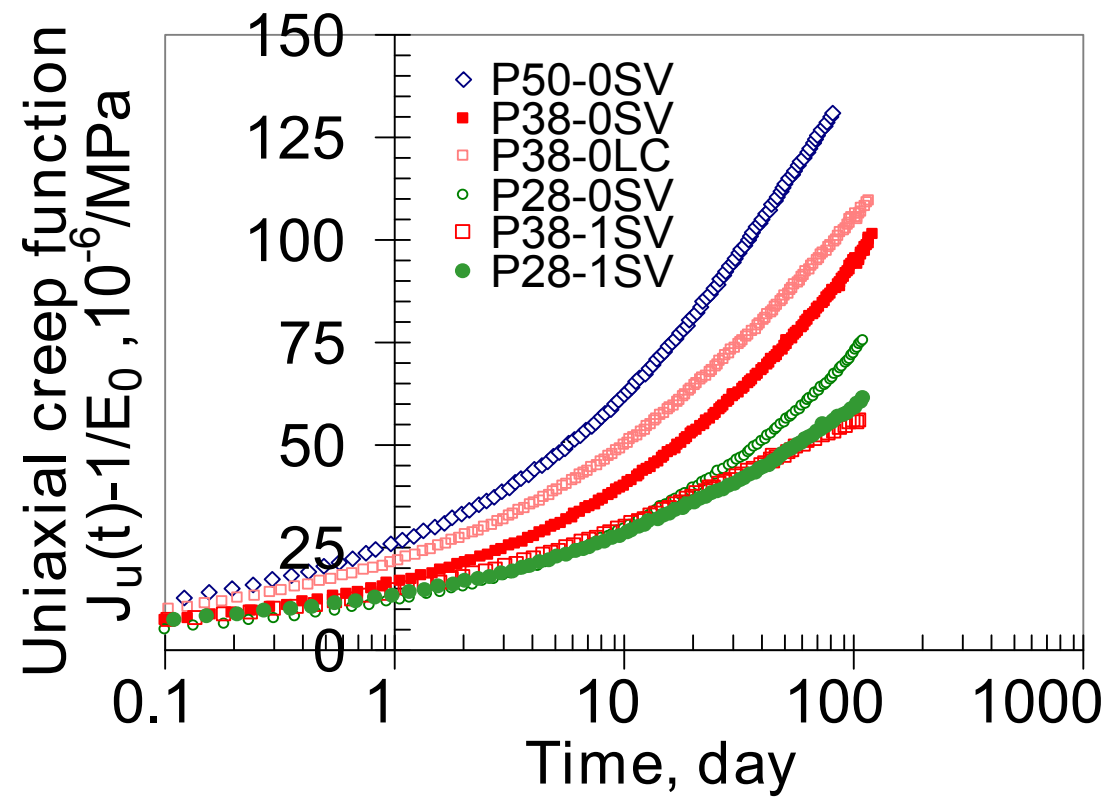

Figure 2: Uniaxial basic creep functions of cement paste samples obtained by uniaxial compressive creep testing. Experiments performed at LCPC (Paris, France), started by R. Le Roy and followed by F. Le Maou [16]. 


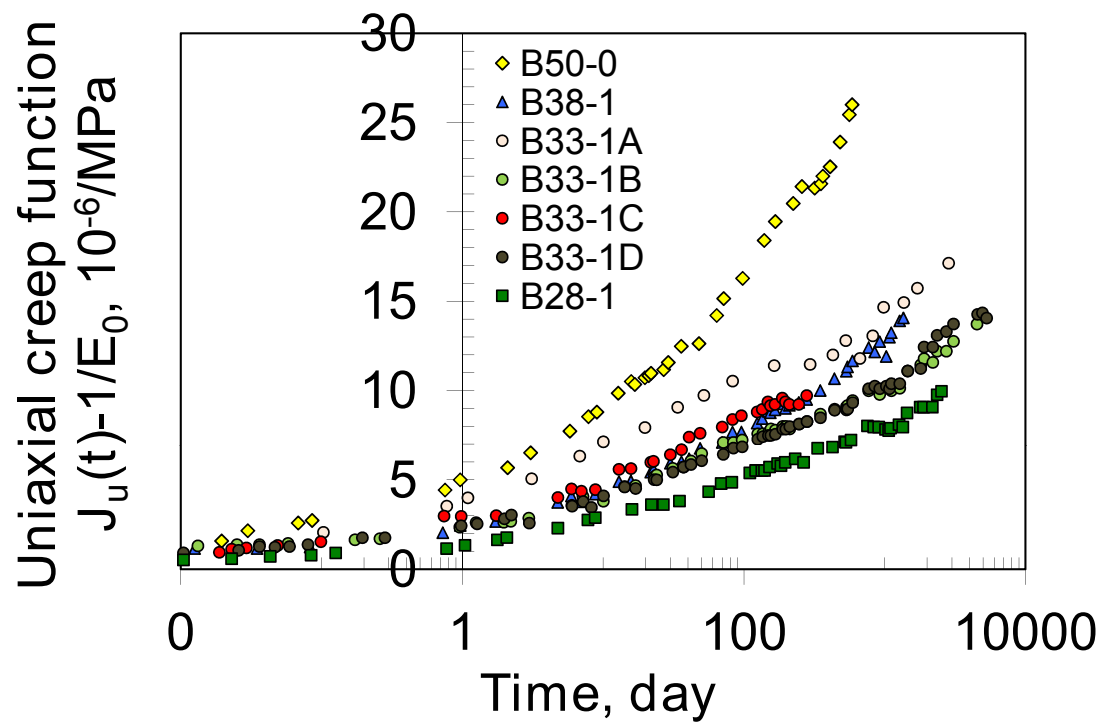

Figure 3: Uniaxial basic creep functions of concrete obtained from uniaxial compressive creep testing. Experiments performed at LCPC (Paris, France), started by R. Le Roy and followed by F. Le Maou [16].

decreases when the volume fraction of aggregates increases, though scattering hides this trend partially for sample B33-1B.

Microindentation creep experiments on cement pastes yielded contact creep functions $L(t)-1 / M_{0}$, which are displayed in Fig. 4. The following trends can be observed: the greater the water-to-cement ratio $w / c$ was, the greater the magnitude of the creep strain was, and creep decreased with an addition of silica fume. Samples with different clinkers but with the same mix proportions (i.e., samples P38-0SV and P38-0LC) exhibited almost identical creep. Note that the trends observed on the creep properties of cement pastes from microindentation test are qualitatively identical to the trends observed by macroscopic uniaxial compression test. 


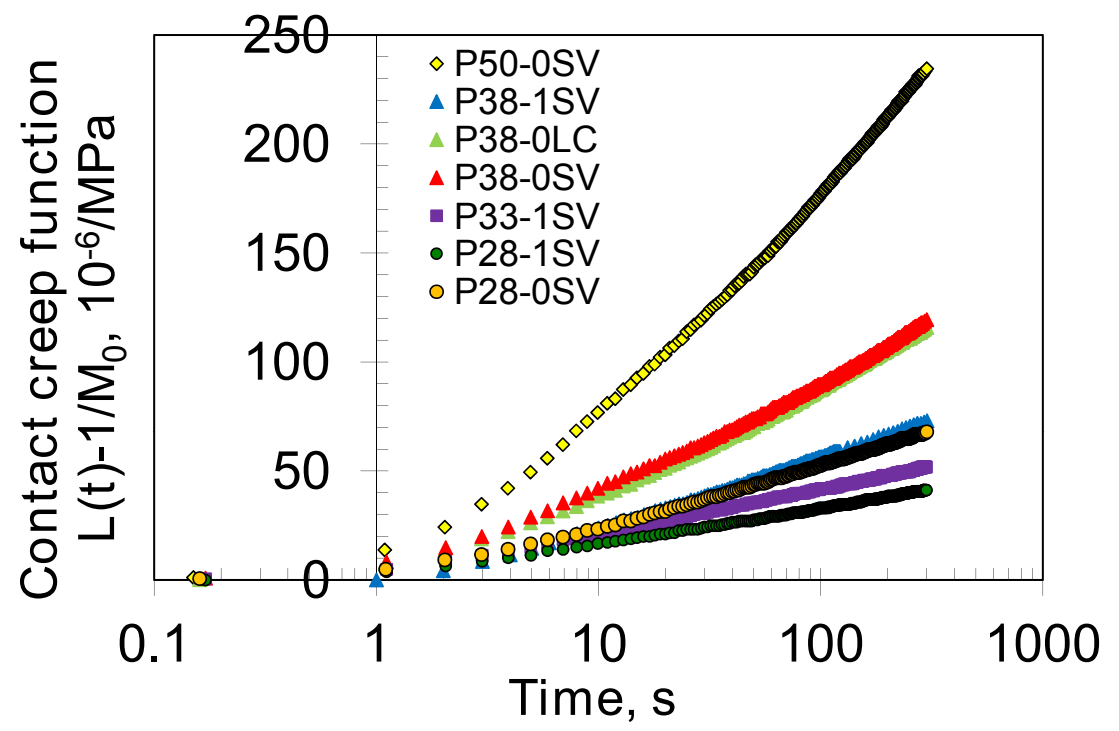

Figure 4: Contact creep functions $L(t)-1 / M_{0}$ of cement paste samples obtained by microindentation. For each sample, out of the 5 experiments performed, only the median curve is displayed.

\subsection{Direct comparison of microindentations on cement paste with uniaxial} compressions on cement paste

In this section, we aim at comparing results obtained by microindentation test with results obtained by regular macroscopic uniaxial testing, both in terms of elastic properties and in terms of creep properties.

For what concerns elastic properties, we explained in Sec. 2.4 how the indentation modulus $M_{0}$ of each sample was measured on each tested cement paste. Assuming a Poisson's ratio $\nu=0.20$ for the samples, Eq. (3) enabled to calculate the Young's modulus $E_{0}$ of the indented cement pastes. The Young's moduli of the cement samples manufactured in 1992 were measured by Marchand by regular macroscopic compression [17]. Both sets of data are displayed in Fig. 5. The agreement between the Young's modulus of 


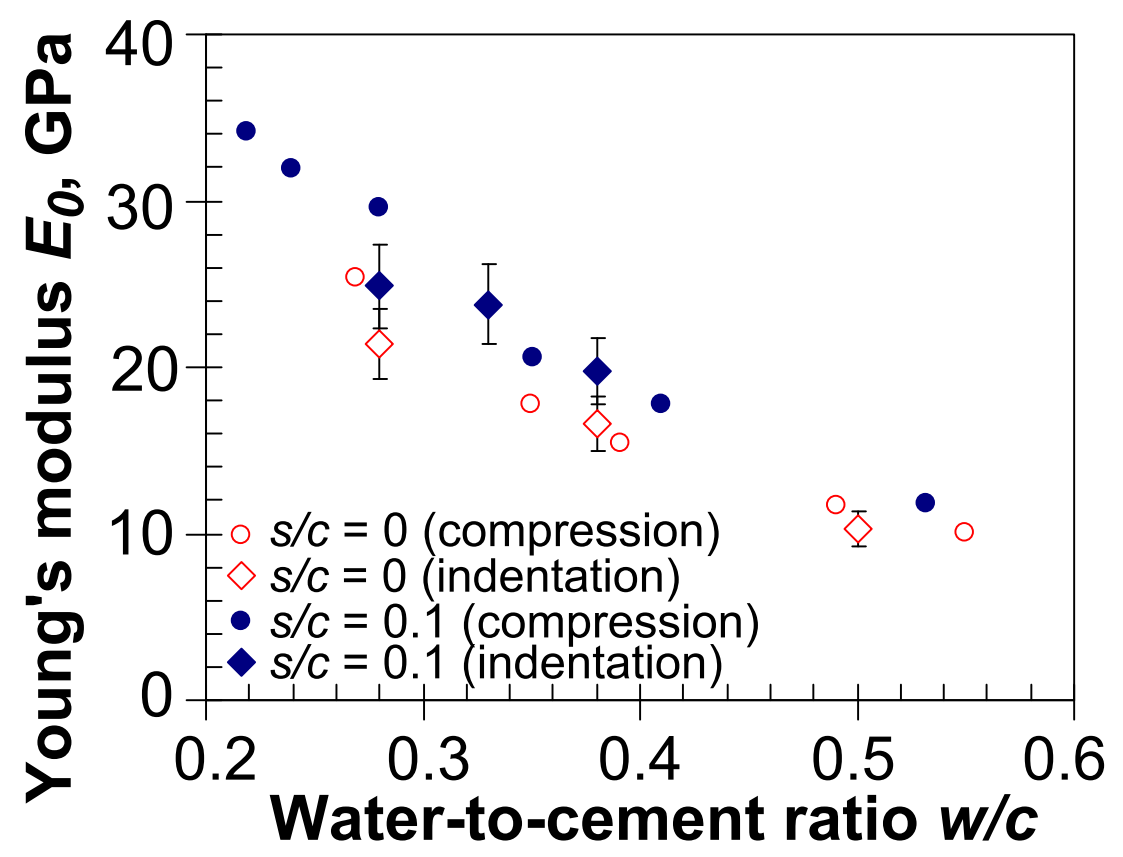

Figure 5: Young's modulus $E_{0}$ of the cement paste samples, determined by indentation test when assuming a Poisson's ratio $\nu=0.20$ and determined by macroscopic uniaxial compression test. $s / c$ stands for the mass ratio of silica fume to clinker. Experimental data for compression is from [17].

the cement pastes prepared in 2011 for indentation test and of the cement pastes prepared in 1992 for uniaxial testing is excellent, which proves that, by using similar raw materials and protocols of preparation, very similar cement pastes were prepared, although almost 20 years apart.

We now aim at comparing directly the creep functions obtained by uniaxial test and by microindentation test. In order to do so, we focus on sample P38-0SV, on which a microindentation creep experiment with a 1800-secondslong holding phase was performed. Both the derivative $d L / d t$ with respect to time of the contact creep function obtained by microindentation test and 
the derivative $d J_{u} / d t$ of the uniaxial creep function obtained by macroscopic uniaxial test are displayed in Fig. 6. One readily observes that, over the half hour compared, the rates measured by the two techniques differed by one or even two orders of magnitude. In addition, a linear regression of this plot in a log-log scale shows that, from 1 minute to 30 minutes, the rate of the creep function measured by uniaxial test decreased as $t^{-0.51}$ while the rate of the creep function measured by microindentation test decreased as $t^{-0.99}$. From this simple comparison performed directly on creep function, we conclude that the microindentation technique does not provide the same creep function as macroscopic uniaxial test.

\subsection{Comparison of long-term logarithmic kinetics of creep}

\subsubsection{Principle}

From the microindentation creep data on cement pastes displayed in Fig. 4 , one observes very clearly that, on the last two decades of the test, creep was logarithmic with respect to time. For the microindentation performed on sample P38-0SV with a 1800-seconds-long holding phase, creep was logarithmic on almost 3 decades (see Fig. 7c). Although less clearly, such logarithmic kinetics of creep can also be observed on about one decade for what concerns the uniaxial creep data on cement paste (see Fig. 2) and on about one to two decades for the data on concrete (see Fig. 3). Moreover, this kinetics is reminiscent of the long-term basic creep of cementitious materials, which, as proposed by several, can be well modeled by a logarithmic function of time $[2,29]$. Therefore, those observations suggest that not only yearslong uniaxial creep experiments on concrete and months-long uniaxial creep experiments on cement paste, but - more surprisingly - also minutes-long 


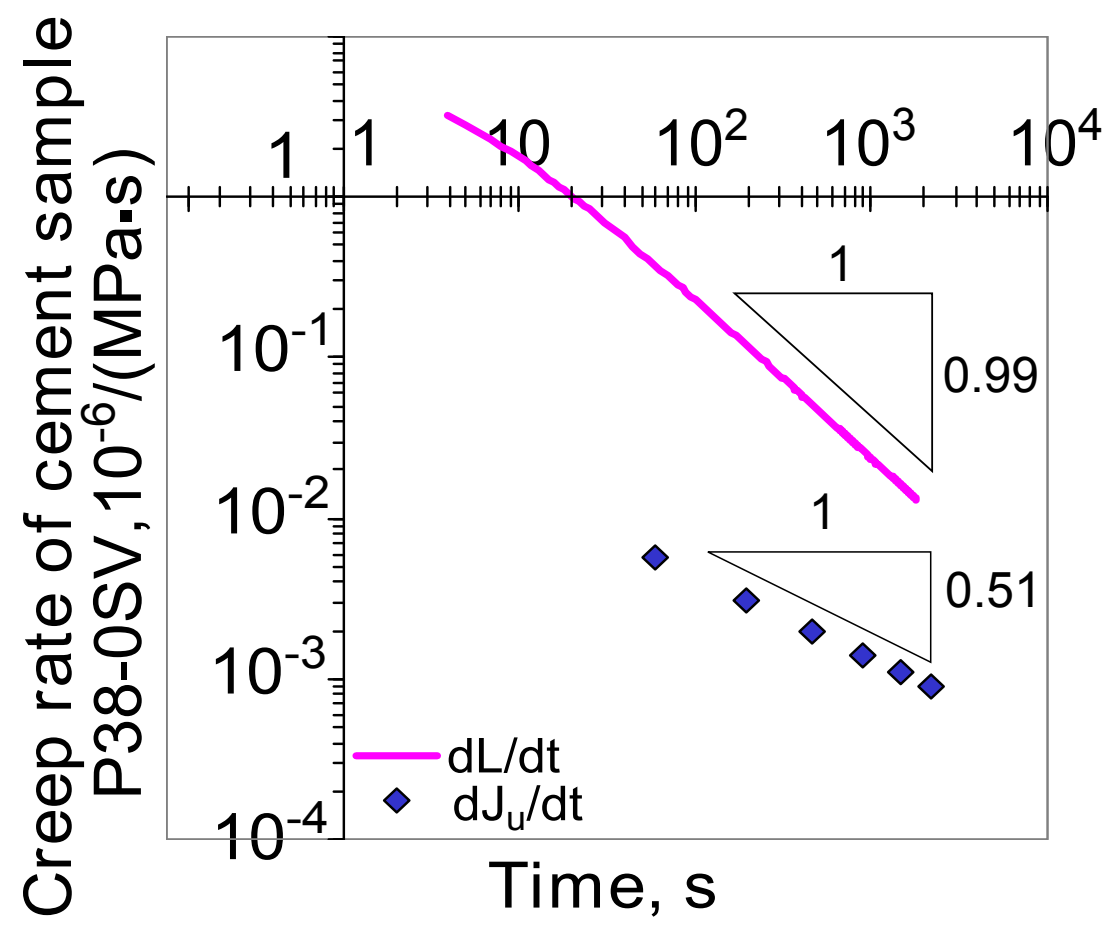

Figure 6: Derivatives with respect to time of the contact creep compliance obtained by microindentation test and of the uniaxial creep compliance obtained by macroscopic compression test on cement paste sample P38-0SV. 
microindentation creep experiments on cement paste were all long enough in order to reach the long-term creep of the tested material, which exhibits a logarithmic kinetics.

In order to compare quantitative parameters, we fitted the measured creep data with logarithmic functions. More precisely, the indentation creep function obtained on cement paste was fitted with:

$$
L(t)-\frac{1}{M_{0}}=\frac{\ln \left(t / \tau_{i}+1\right)}{C_{i}}
$$

The uniaxial creep function obtained by uniaxial compression was fitted with:

$$
J_{u}(t)-\frac{1}{E_{0}}=\frac{\ln \left(t / \tau_{u}+1\right)}{C_{u}}
$$

The parameters $C_{i}$ and $C_{u}$ are termed contact creep modulus and uniaxial creep modulus, respectively. The greater they are, the lower the amplitude of creep is. In the case of uniaxial testing, in order to differentiate between values obtained for cement paste and for concrete, the following notations are used: when the fit is performed for cement paste, the fitted parameters $\tau_{u}$ and $C_{u}$ are noted $\tau_{u, c e m}$ and $C_{u, c e m}$, respectively; when the fit is performed for concrete, the fitted parameters $\tau_{u}$ and $C_{u}$ are noted $\tau_{u, c o n}$ and $C_{u, c o n}$, respectively.

With such a choice of fitting functions, each creep function is condensed into 2 parameters: a characteristic time (noted $\tau_{u}$ when obtained from uniaxial testing and $\tau_{i}$ when obtained from indentation testing) and a creep modulus (noted $C_{u}$ when obtained from uniaxial testing and $C_{i}$ when obtained from indentation testing). The characteristic time characterizes the 
time at which creep starts exhibiting a logarithmic kinetics. The creep modulus governs the rate of this long-term kinetics:

$$
\begin{aligned}
\frac{d J_{u}}{d t} & \approx \frac{1}{C_{u} t} \text { if } t \gg \tau_{u} \\
\frac{d L}{d t} & \approx \frac{1}{C_{i} t} \text { if } t \gg \tau_{i}
\end{aligned}
$$

Figure 7 displays the best fits obtained with the functions introduced in Eqs. (6) and (7). The best-fit parameters are presented in Tables 5, 6, and 7. Table 5 shows that the characteristic time needed to reach logarithmic kinetics varied tremendously with the type of solicitation: this characteristic time was on the order of a day for uniaxial creep experiments on cement paste or on concrete, but was on the order of a second for the microindentation creep experiments on cement paste. Said otherwise, microindentation enabled to reach the logarithmic kinetics of creep orders of magnitude faster than regular macroscopic test.

\subsubsection{Comparison from paste to paste}

The contact creep modulus $C_{i}$ fitted on the microindentation creep experiments on cement paste and the uniaxial creep modulus $C_{u, c e m}$ fitted on the uniaxial creep experiments on cement paste are given in Table 6 and displayed in Fig. 8 with respect to each other. Fitting a linear relation to the experimental data through zero yielded $C_{i}=1.198 C_{u, c e m}$ with an average distance of the data points to the fitted line of $13.7 \mathrm{GPa}$. At least, the contact creep moduli and the uniaxial creep moduli were of the same order of magnitude, while the creep functions measured uniaxially and by indentation differed by more than one order of magnitude (see Fig. 8). However, given 

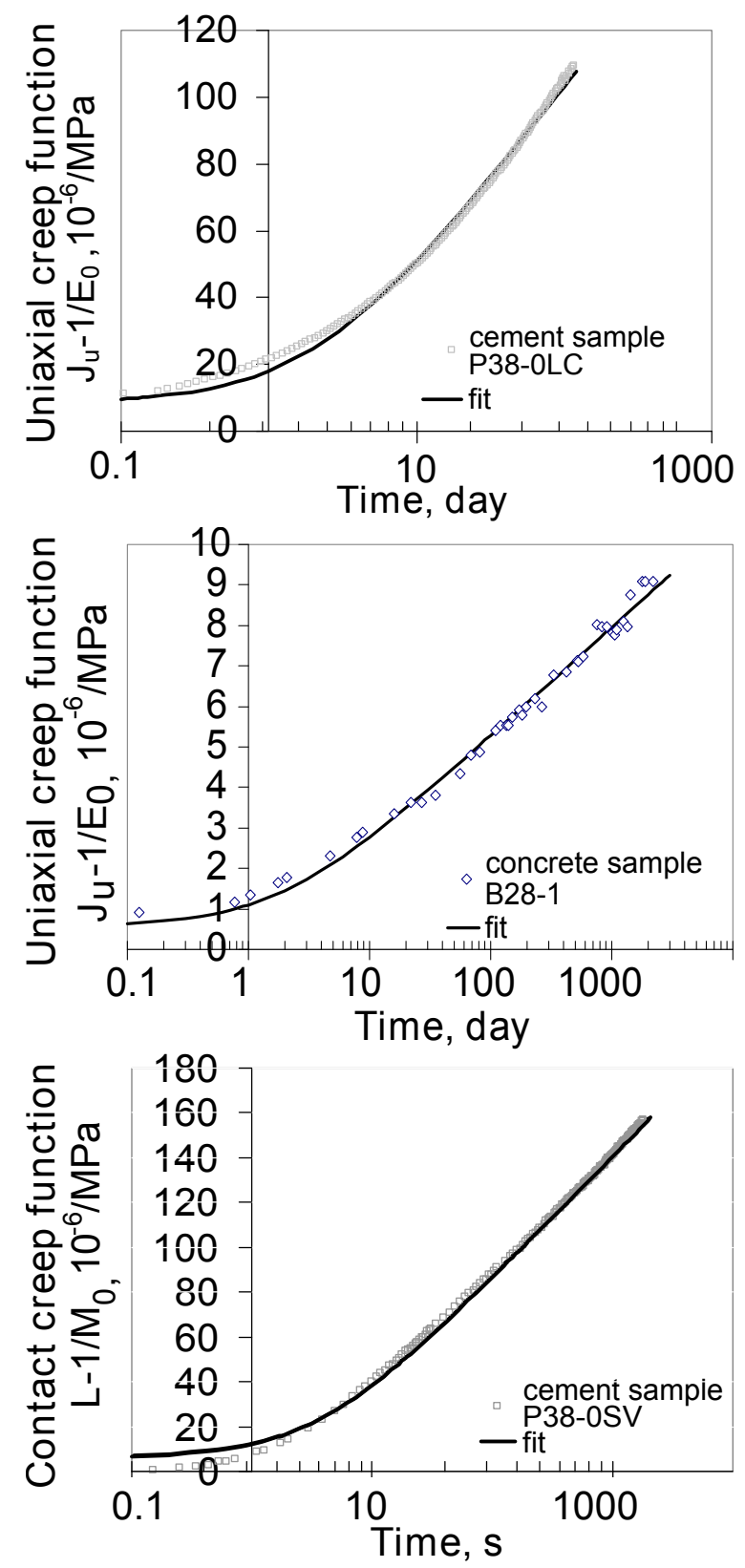

Figure 7: Examples of basic creep functions and of the best fits obtained with Eq. (6) or Eq. (7): a) uniaxial creep function obtained by uniaxial compression of cement paste P38-0LC, b) uniaxial creep function obtained by uniaxial compression of concrete B28-1, and c) contact creep function obtained by microindentation of cement paste P38-0SV. 


\begin{tabular}{l||c|c}
\hline Sample & $\tau_{u, c e m}$ (day) & $\tau_{i}$ (second) \\
\hline \hline P28-0SV & 4.8 & $2.2 \pm 0.6$ \\
P38-0SV & 3.7 & $3.2 \pm 0.7$ \\
P50-0SV & 2.6 & $2.4 \pm 0.8$ \\
P28-1SV & 2.1 & $1.5 \pm 0.4$ \\
P33-1SV & - & $1.3 \pm 0.4$ \\
P38-1SV & 0.9 & $2.4 \pm 0.6$ \\
P38-0LC & 2.1 & $3.3 \pm 0.3$ \\
\hline \hline Sample & $\tau_{u, \text { con }}($ day) & \\
\hline B28-1 & 2.2 & - \\
B38-1 & 2.5 & - \\
B50-0 & 2.3 & - \\
B33-1A & 0.2 & - \\
B33-1B & 1.4 & - \\
B33-1C & 0.5 & - \\
B33-1D (data until 5320 days) & 2.8 & - \\
B33-1D (data until 1800 days) & 1.1 & - \\
\hline
\end{tabular}

Table 5: Characteristic time $\tau_{u}$ obtained by uniaxial compression creep experiment and $\tau_{i}$ obtained by indentation creep experiment. 


\begin{tabular}{l||cc}
\hline Sample & $C_{u, c e m}(\mathrm{GPa})$ & $C_{i}(\mathrm{GPa})$ \\
\hline \hline P28-0SV & 47.89 & 75.16 \\
P38-0SV & 39.42 & 39.68 \\
P50-0SV & 29.49 & 20.89 \\
\hline P28-1SV & 75.16 & 124.5 \\
P33-1SV & - & 104.5 \\
P38-1SV & 94.10 & 67.46 \\
\hline P38-0LC & 40.86 & 39.74 \\
\hline
\end{tabular}

Table 6: Contact creep modulus $C_{i}$ obtained by microindentation creep experiment on cement paste and uniaxial creep modulus $C_{u, c e m}$ obtained by uniaxial compression creep experiment on cement paste.

the relative poorness of the fit displayed in Fig. 8, we conclude that the logarithmic creep measured by microindentation did not enable us to precisely retrieve the amplitude of the logarithmic creep measured by macroscopic uniaxial test on cement paste.

\subsubsection{Comparison from paste to concrete}

The contact creep moduli $C_{i}$ were measured at the scale of cement paste, while the uniaxial creep moduli $C_{u, c o n}$ were measured at the scale of concrete: those two sets of moduli can therefore not be directly compared. In order to make a comparison possible, results obtained at the scale of cement paste must be upscaled to the scale of concrete. We performed this upscaling by using homogenization techniques within the frame of linear viscoelasticity. For details on how to perform homogenization of materials that creep logarithmically with respect to time, we refer to the work of Vandamme and Ulm 


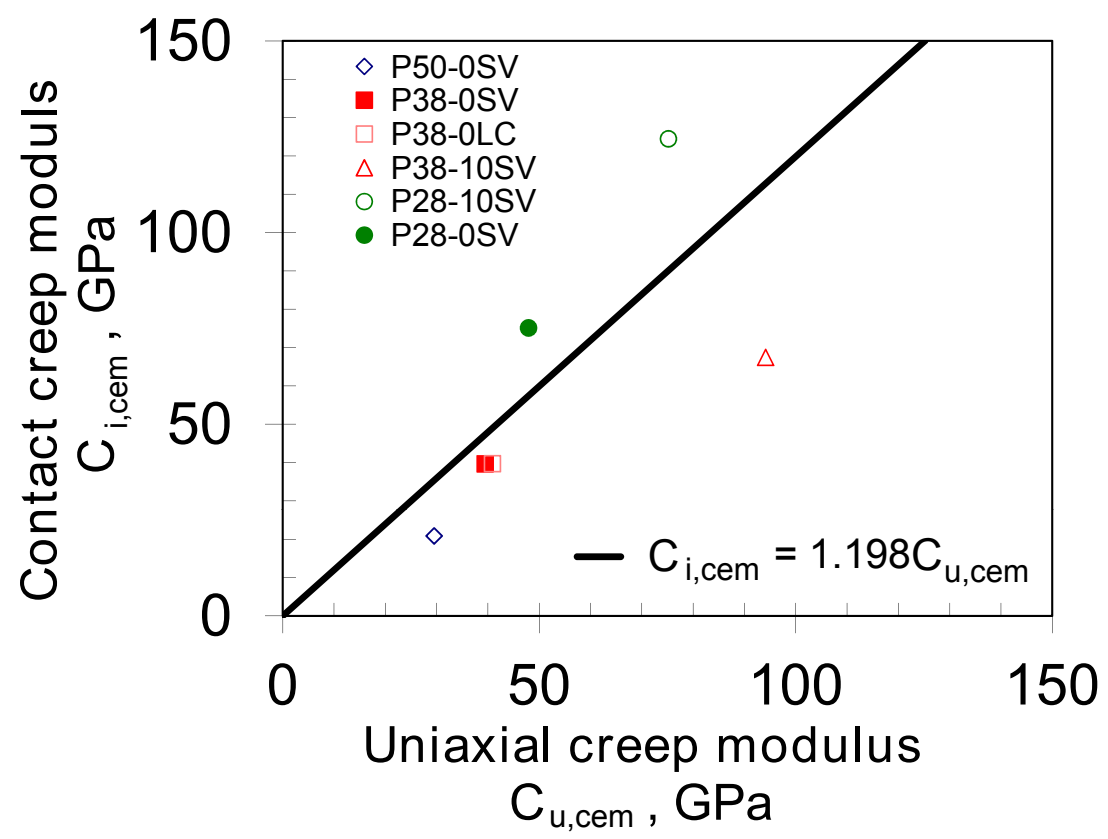

Figure 8: Uniaxial creep modulus $C_{u, c e m}$ versus contact creep modulus $C_{i}$ for cement paste samples. 
[34]. In particular, these authors showed that, if a cement paste creeps logarithmically with respect to time in the long term, the concrete of which it is made (i.e., a mixture of creeping cement paste with non-creeping aggregates) should also creep logarithmically in the long term. Also, they showed that, if the cement paste creeps deviatorically in the long term i.e., with no volume change, a concrete made with this paste should also creep deviatorically in the long term. Making use of a Mori-Tanaka scheme, which is well adapted to matrix-inclusions morphologies, they showed that the contact creep modulus $C_{i, c o n}$ of the concrete can be estimated from the contact creep modulus $C_{i}$ of the cement paste with:

$$
C_{i, \text { con }}=C_{i} \frac{2+3 f_{\text {agg }}}{2\left(1-f_{\text {agg }}\right)}
$$

where $f_{\text {agg }}$ is the volume fraction occupied by the aggregates in the concrete. Applying the above equation, for each concrete sample we estimated its contact creep modulus $C_{i, c o n}$ from the contact creep modulus $C_{i}$ measured on the cement paste of which this concrete was made. Table 7 provides both this contact creep modulus $C_{i, c o n}$ estimated by microindentation tests performed at the scale of the paste and the uniaxial creep modulus $C_{u, c o n}$ measured by uniaxial compression of the concrete sample. Figure 9a displays those two creep moduli with respect to each other for all concrete samples. Although this relation is roughly linear, we note that the data point associated to sample B33-1D falls outside this linear relationship.

The uniaxial creep function of sample B33-1D, already displayed in Fig. 3 together with the uniaxial creep functions of all other concrete samples tested, is displayed again in Fig. 10. On this latter figure, one can clearly 
a)

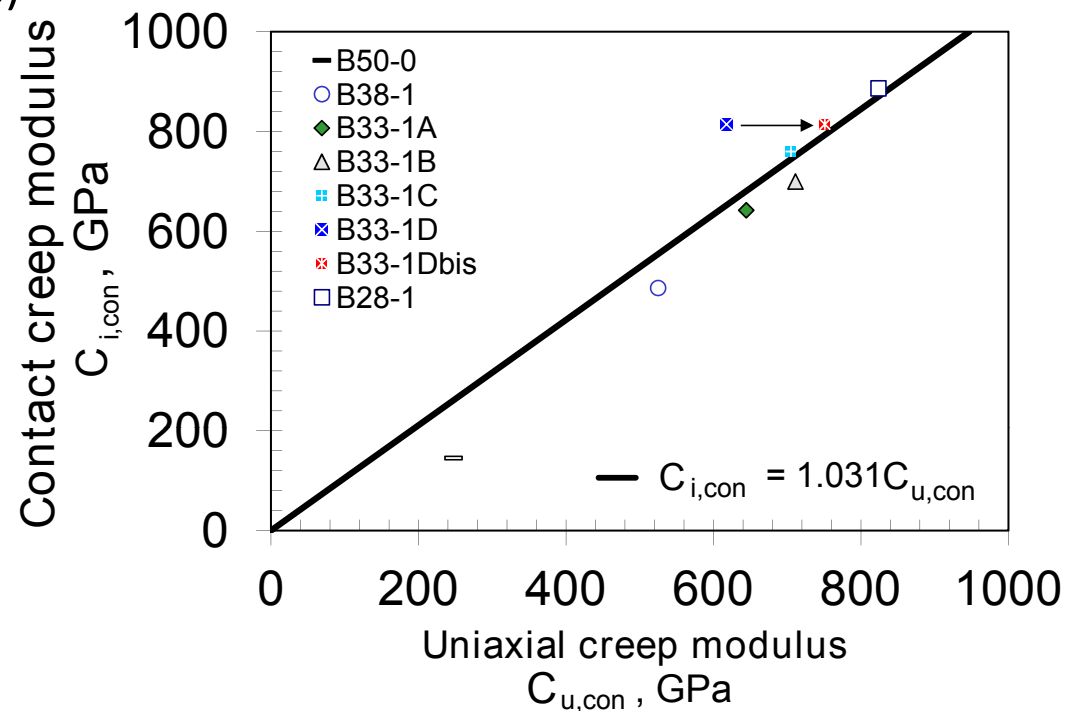

b)

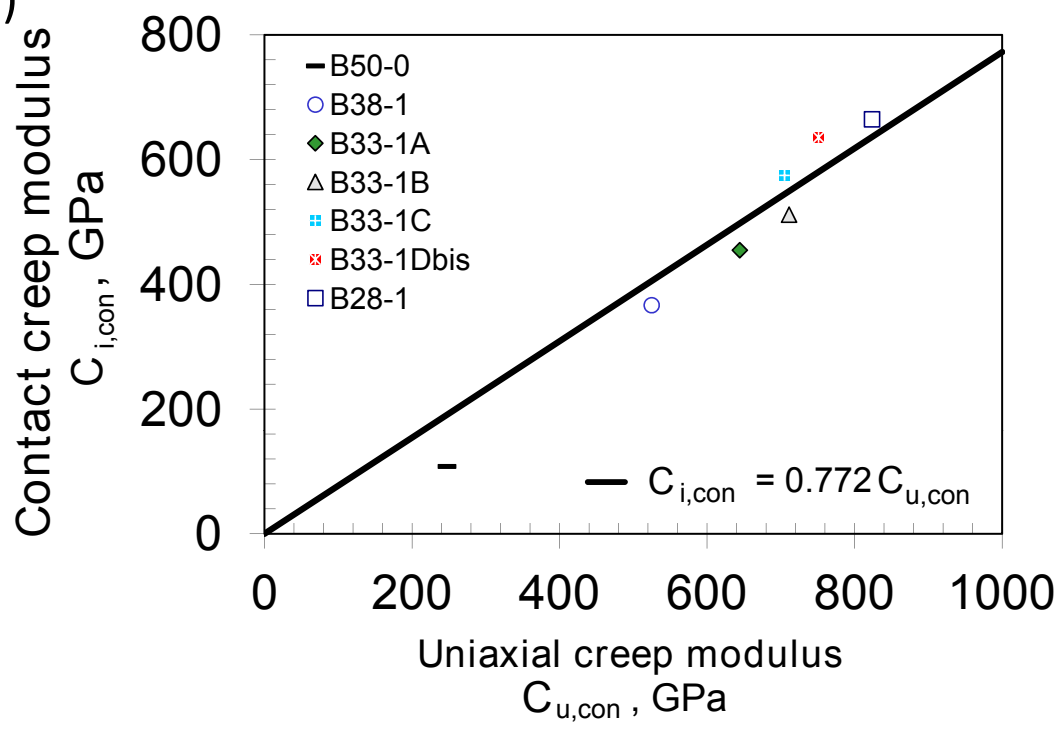

Figure 9: Uniaxial creep modulus $C_{u, c o n}$ measured by uniaxial compression creep experiments on concrete versus contact creep modulus $C_{i, c o n}$ of concrete estimated from microindentation creep experiments performed on cement paste, by considering, for the upscaling from the scale of cement paste to the scale of concrete, a) a Mori-Tanaka scheme and b) the upscaling model of $\mathrm{Vu}$ et al. [35]. 


\begin{tabular}{l||cc}
\hline Sample & $C_{u, \text { con }}(\mathrm{GPa})$ & $C_{i, \text { con }}(\mathrm{GPa})$ \\
\hline \hline B28-1 & 823.6 & 886.5 \\
\hline B38-1 & 524.8 & 486.4 \\
\hline B33-1A & 644.3 & 642.2 \\
B33-1B & 711.1 & 699.8 \\
B33-1C & 705.0 & 759.9 \\
B33-1D (data until 5320 days) & 617.6 & \\
B33-1D (data until 1800 days) & 751.0 & \\
\hline B50-0 & 247.3 & 145.7 \\
\hline
\end{tabular}

Table 7: Uniaxial creep modulus $C_{u, c o n}$ measured by uniaxial compression creep experiments on concrete and contact creep modulus $C_{i, c o n}$ of concrete estimated from microindentation creep experiments performed on cement paste.

observe that the creep function of this concrete exhibited a nice logarithmic dependency on time after about a dozen of days, but that the creep rate sharply increased after about 1800 days. Wondering whether the data gathered after 1800 days was still fully representative of the basic creep of the sample, we performed again the analysis of the data on this sample, by considering only data points up to 1800 days. A fit of the function given in Eq. (7) to this new set yielded a new uniaxial creep modulus $C_{u, \text { con }}=751.0$ $\mathrm{GPa}$ and a new characteristic time $\tau_{u, c o n}=1.1$ day for this sample. The $C_{i, \text { con }^{-v} \text {-versus- }} C_{u, c o n}$ relationship with this corrected uniaxial creep modulus is also displayed in Fig. 9a.

One can observe that the correlation between uniaxial creep modulus measured by macroscopic uniaxial test and contact creep modulus estimated 


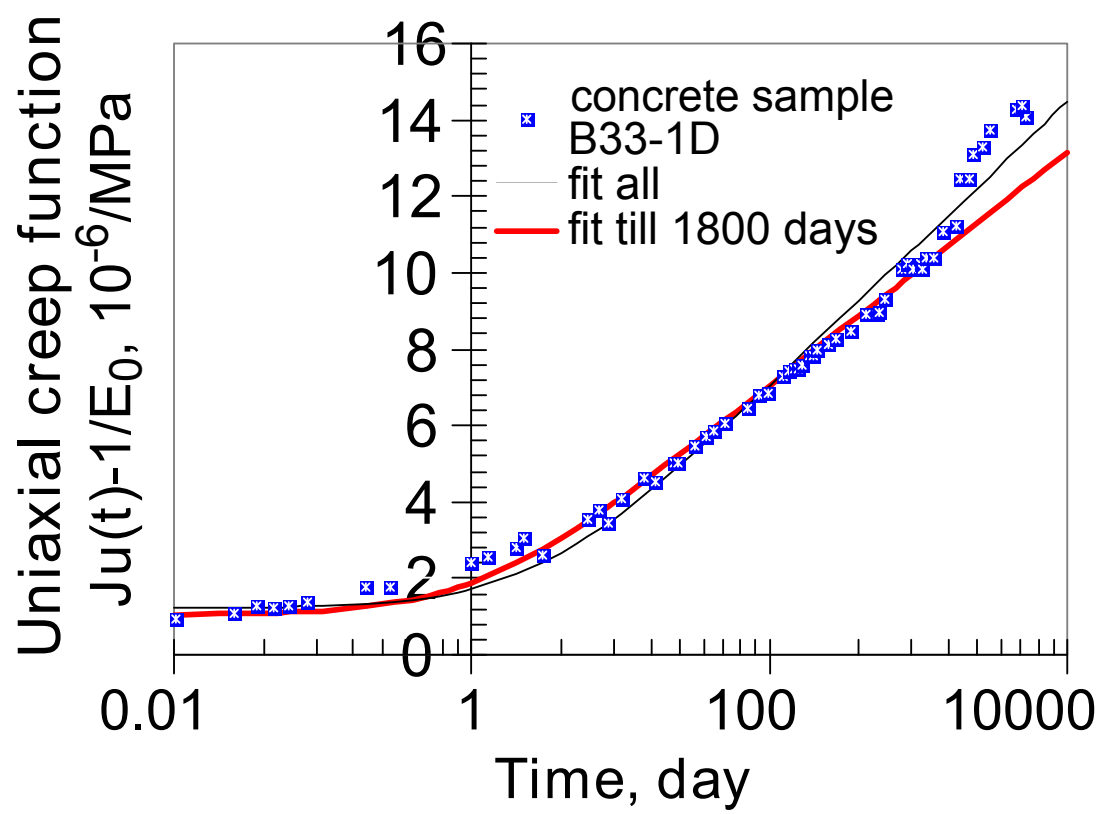

Figure 10: Basic creep function of concrete sample B33-1D, together with Eq. (7) fitted on all data points and with Eq. (7) fitted on data points until 1800 days only.

by microindentation at the scale of the cement paste is now much better. Fitting a linear relation to the experimental data with the corrected data point for sample B33-1D yielded $C_{i, c o n}=1.031 C_{u, c o n}$ with an average distance of the data points to the fitted line of $32.8 \mathrm{GPa}$ : the agreement between direct measurements of long-term creep properties of concrete and estimations based on microindentation tests at the scale of the cement paste is excellent. Better than the comparison on cement paste, the creep moduli of various concrete samples estimated by microindentation at the scale of cement paste compared well with the creep moduli measured by macroscopic creep test, in spite of an extra step of homogenization. 


\section{Discussion}

\subsection{On the coefficient between contact and uniaxial creep modulus}

For concrete, an excellent agreement was found between macroscopic measurements and estimates based on microindentation tests (see Fig. 9a), and the coefficient that enables to translate a contact creep modulus $C_{i, c o n}$ into a uniaxial creep modulus $C_{u, c o n}$ was found to be equal to $C_{u, c o n}=0.970 C_{i, c o n}$. Why such a coefficient? In elasticity the indentation modulus $M_{0}$ is linked to the Young's modulus $E_{0}$ through Eq. (3). Considering that, on the long term, the material of interest (here concrete) is linear viscoelastic and creeps only deviatorically (i.e., with no volume change), an application of the $s$-multiplied Laplace transform to Eq. (3) yields the theoretical relation $C_{u, \text { con }}=\left(1-0.5^{2}\right) C_{i, \text { con }}=0.75 C_{i, c o n}$. Therefore, we observe a discrepancy between the theoretical coefficient and the one used experimentally to convert the contact creep modulus into a uniaxial one. As will be seen in the next section, this discrepancy may be explained by the choice of homogenization scheme that we used to estimate the contact creep modulus of the concrete from the one of the paste.

\subsection{On the choice of homogenization scheme}

In order to predict the creep of concrete from the creep of the paste measured by indentation, we needed to employ a homogenization scheme, namely the Mori-Tanaka scheme (see Eq. 10). At high volume fractions of inclusions, the estimation given by the scheme is less accurate [11]. Therefore, one may want to try other schemes. As an alternative, we employed the upscaling model proposed by $\mathrm{Vu}$ et al. [35] for bidisperse suspensions of noncolloidal 
particles in yield-stress fluids. For such suspensions, the shear modulus $G$ of the suspension is related to the shear modulus $G_{0}$ of the suspending fluid through $G / G_{0}=\left(1-f / f_{m}\right)^{-1.43}$, where $f$ is the volume fraction of the particles and $f_{m}$ a critical volume fraction at which the elastic properties diverge. Adapting their model to our problem of a concrete made of noncreeping aggregates, we translated their formula for viscous properties as: $C_{i, \text { con }}=C_{i}\left(1-f_{\text {agg }} / f_{\text {agg }, m}\right)^{-1.43}$ or $C_{u, c o n}=0.75 C_{i}\left(1-f_{\text {agg }} / f_{\text {agg }, m}\right)^{-1.43}$, where $f_{\text {agg,m }}$ is the critical volume fraction of aggregates above which creep properties should diverge. Fitting this relation to the experimental measurements yielded very satisfactory results for a critical volume fraction $f_{\text {agg, } m}=90.4 \%$ of aggregates. For such parameter, a linear fit through zero of the relation

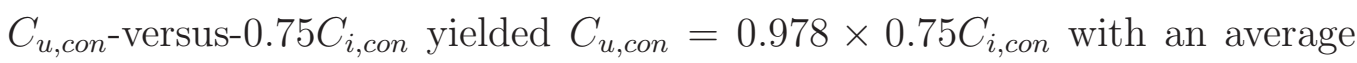
distance of the data points to the fitted line of 48.4 GPa (see Fig. 9b). Therefore, we conclude that the discrepancy observed with the Mori-Tanaka scheme (i.e., the fact that the coefficient of proportionality observed between the measured uniaxial creep modulus of concrete and the contact creep modulus of concrete predicted with the Mori-Tanaka scheme did not correspond to the value 0.75 expected theoretically) is likely due to the fact that the Mori-Tanaka scheme is not adapted to systems with high volume fractions of inclusions. At such high volume fractions, the upscaling model proposed by $\mathrm{Vu}$ et al. [35] may be more relevant. However, in turn, one should note that the use of the Mori-Tanaka scheme requires the knowledge of the mechanical properties of the individual phases and of their volume fractions only, while the use of the upscaling model of $\mathrm{Vu}$ et al. requires the additional knowledge of a critical volume fraction $f_{\text {agg,m }}$ of aggregates. 


\subsection{On the ability of indentation to characterize long-term creep}

The comparison in the previous section shows that a 5-minutes-long microindentation test at the scale of the cement paste enables to quantitatively predict the long-term logarithmic creep kinetics of a concrete sample. This result, although already proposed by Vandamme and Ulm [33], is surprising, since this long-term logarithmic kinetics is only reached after days at the scale of macroscopic samples, or even after years at the scale of structures [3]. According to Vandamme and Ulm, the ability to characterize longterm creep kinetics so fast by microindentation is apparently not due to the fact that microindentation probes a much smaller volume than macroscopic experiments, or probe those volumes at much higher strains than regular macroscopic test. They proposed the tentative explanation that this ability is due to the fact that microindentation probes the material at much greater stresses than macroscopic test. In our study, for uniaxial creep experiments, we observed no significant difference between the characteristic time needed to reach a logarithmic kinetics of creep on cement paste or on concrete (see Table 5). This observation further suggests that the characteristic time needed to reach a logarithmic kinetics of creep is not governed by the size of the system; on the other hand, the difference in the size of the concrete samples (the length of which was $1000 \mathrm{~mm}$ and the diameter of which was $160 \mathrm{~mm}$ ) and of the cement paste samples (the length of which was $160 \mathrm{~mm}$ and the diameter of which was $20 \mathrm{~mm}$ ) may have been not sufficient to observe significant differences between the characteristic times for the two sets of samples. In addition, since this characteristic time did not differ much between cement samples and concrete samples, we can also 
conclude that the heterogeneity of the system does not modify the duration needed to reach a long-term creep: indeed, concrete samples are more heterogeneous than cement paste samples, in the sense that concrete is itself a mixture of cement paste with aggregates.

\subsection{On the quality of the creep experiments}

The quality of the correlation between microindentation results and macroscopic uniaxial results was much better at the scale of the concrete than at the scale of the cement paste (see Figs. 8 and 9). Such a result is quite surprising, since comparing results at the scale of a concrete sample required to homogenize results obtained by microindentation at the scale of the cement paste: by doing so, since homogenization schemes such as the Mori-Tanaka scheme only provide estimates of the homogenized properties, one could have expected that the quality of the correlation would have been worse at the scale of the concrete than at the scale of the cement paste. Our opinion is that the relatively poor correlation on cement paste samples is due to the difficulty of performing creep experiments on cement samples. In general, performing creep experiments on cementitious materials is tricky and, even when great care is taken, a dispersion of the long-term creep results of about $16.5 \%$ can be expected on concrete samples tested 28 days after casting [5]. For younger samples, this dispersion is rather on the order of $20 \%$ [5]. On cement paste samples, even more dispersion should be expected, since preparing the samples proves to be very delicate, in spite of the fact that cement paste samples are smaller than concrete samples. An example of such a difference in the difficulty of preparing both sets of specimen is the fact that cement paste samples needed to be rotated for a few hours after casting in 
order to prevent segregation, while concrete samples did not.

In order to obtain Fig. 9b from Fig. 9a, we needed to perform a new analysis of the creep data of sample B33-1D. For this sample, instead of considering all the data available on the 5320 days (i.e., about 14.5 years), we only considered data on about 1800 days (i.e., about 5 years), because of a kink in the data at about 1800 days, that we considered as spurious (see Fig. 10). Although the spuriousness of this kink can be discussed, we want to underline how difficult and tedious running creep experiments on such long periods is. Since the objective of such experiments is to measure basic creep, on several years the temperature must be well controlled and all hygric exchanges must be prevented. The difficulty is also enhanced by the fact that basic creep strain is measured by difference between the strains measured on a loaded sample and on an unloaded sample (see Sec. 2.2): therefore, basic creep will be correctly measured only if temperature is well controlled and hygric exchanges are prevented for both samples, thus increasing the risks of experimental error. In our present study, experimental error due to temperature variations must have been negligible, since all samples for compressive creep experiments and autogenous shrinkage experiments were located in the same room and thus at the same temperature. In contrast, since upon years drying can occur even for samples tightly sealed with selfsealing aluminum foil [28], experimental error due to long-term drying can not be discarded, in particular for sample B33-D.

As an alternative to tedious years-long macroscopic experiments, minuteslong microindentation testing would prove to be very handy. And our work showed that such microindentation testing makes it possible to characterize 
precisely the long-term logarithmic kinetics of creep of cementitious materials. As a counterpart, this result means that microindentation testing cannot give access to the short-term kinetics of those materials. Consequently, microindentation testing should be used as a complement to shorter macroscopic creep experiments: the macroscopic experiments would enable to characterize the short-term creep of the material and should be sufficiently long to reach the long-term logarithmic kinetics of creep; while microindentation tests run in parallel would enable to characterize the rate of this logarithmic kinetics of creep. For practical use, other sources of creep (e.g., drying creep) would need to be added to the long-term basic creep determined in such a manner.

\section{Conclusions}

This work was dedicated to comparing microindentation creep experiments on cement paste with macroscopic uniaxial creep experiments on both cement paste and concrete. Samples for uniaxial experiments were manufactured in 1992, while samples for indentation test were manufactured in 2011. Although the two sets of samples were prepared almost 20 years apart, we used virtually the same raw materials and employed the same procedures of preparation, so that the mechanical properties of both sets of cement pastes could be expected to be very close to each other (see Fig. 5).

Uniaxial creep experiments lasted for years on concrete samples and for months on cement paste samples. In contrast, microindentation creep experiments (performed at the scale of cement paste) only lasted for minutes. The creep rate measured by microindentation differed by one to two orders of magnitude from the creep rates measured during the first thirty minutes 
of the macroscopic uniaxial experiments (see Fig. 6): microindentation did not provide access to the short-term creep of the tested cement pastes.

For all experiments, after a transient period, the basic creep was well captured by a logarithmic function of time. The amplitude of the rate of this logarithmic kinetics of creep depends on a creep modulus, called uniaxial creep modulus for uniaxial creep experiments and contact creep modulus for microindentation creep experiments. We compared the contact creep moduli with the uniaxial creep moduli. The comparison with macroscopic uniaxial experiments on concrete required to homogenize the microindentation results: this homogenization was performed within the frame of linear viscoelasticity. Contact creep moduli of concrete were in an excellent agreement with uniaxial creep moduli measured by regular macroscopic test (see Fig. $9 \mathrm{~b})$. This result shows that the rate of long-term creep of concrete can be quantitatively inferred from minutes-long microindentation experiments at the scale of the cement paste. However, the coefficient of proportionality observed between measured uniaxial creep moduli and predicted contact creep moduli did not correspond to the value expected theoretically: this discrepancy was attributed to the inaccuracy of the Mori-Tanaka scheme for systems with high volume fraction of inclusions. At such high volume fractions, the upscaling model proposed by $\mathrm{Vu}$ et al. [35] may be more relevant.

The measured contact creep moduli compared worse with the uniaxial creep moduli on cement paste (see Fig. 8). We attributed this less good agreement to the difficulty of measuring basic creep of cement pastes by regular macroscopic testing. Several factors can make this measurement tricky: difficulty of preparing homogeneous samples (which need to be rotated 
after mixing), need to perform two experiments in parallel (since basic creep is obtained by subtracting autogenous shrinkage to total creep), difficulty of preventing hydric exchanges with the surroundings over long periods of time and scattering due to a smaller volume compared with concrete.

The characteristic time needed to reach a logarithmic kinetics of creep was of a few days with macroscopic uniaxial testing and of a few seconds with microindentation testing. This striking observation - that small-scale experiments enable to reach long-term creep of cementitious materials orders of magnitude faster than macroscopic experiments - was already observed at the scale of nanoindentation testing [34]. This surprising feature is apparently not due to the fact that microindentation or nanoindentation probes small volumes, or probes those volumes at large strains, or probes volumes that are less heterogeneous than macroscopic ones. In contrast, a tentative explanation proposed by Vandamme and Ulm [34] is that indentation testing probes volumes at very large stresses, thus allowing for a fast redistribution of internal stresses within the solid.

Our study shows that microindentation experiments provide access to the long-term kinetics of creep of cementitious materials in minutes. As a counterpart, such microindentation experiments do not allow to characterize the short-term creep of those materials. From an engineering perspective, microindentation could prove very beneficial, when used in parallel with regular macroscopic testing: the latter should only last long enough in order to measure the short-term kinetics of creep, while the rate of the long-term logarithmic creep would be characterized by microindentation. By doing so, the whole basic creep function of cementitious materials could be measured 
precisely and in a more convenient and faster way than is done today.

\section{Acknowledgements}

We express our thanks to H. Noyalet (from Lafarge Research Center) for his help on upgrading the microindenter and to various supports at the Lafarge Research Center for performing the microindentation creep experiments on cement paste. We also thank F. Le Maou (from IFSTTAR) for his help in performing the compressive creep experiments and X. Chateau (from Laboratoire Navier) for interesting discussions regarding upscaling.

[1] ASTM Standard E2546 -7. Standard practice for instrumented indentation testing. ASTM international, West Conshohocken, 2007.

[2] Zdeněk P. Bažant and Sandeep Baweja. Justification and refinements of model B3 for concrete creep and shrinkage 2. Updating and theoretical basis. Materials and Structures, 28(8):488-495, October 1995.

[3] Zdeněk P. Bažant, Mija H. Hubler, and Qiang Yu. Pervasiveness of excessive segmental bridge deflections: wake-up call for creep. ACI Structure Journal, 108(6):766-774, 2011.

[4] Olivier Bernard, Franz-Josef Ulm, and John T Germaine. Volume and deviator creep of calcium-leached cement-based materials. Cement and Concrete Research, 33(8):1127-1136, August 2003.

[5] Jean-Luc Clément and Fabrice Le Maou. Étude de la répétabilité des essais de fluage sur éprouvette de béton. Bulletin des Laboratoires des Ponts et Chaussées, 228(4329):59-69, 2000. 
[6] Georgios Constantinides and Franz-Josef Ulm. The effect of two types of C-S-H on the elasticity of cement-based materials: Results from nanoindentation and micromechanical modeling. Cement and Concrete Research, 34(1):67-80, January 2004.

[7] Georgios Constantinides and Franz-Josef Ulm. The nanogranular nature of C-S-H. Journal of the Mechanics and Physics of Solids, 55(1):64-90, January 2007.

[8] D Davydov, Milan Jirasek, and L Kopecký. Critical aspects of nanoindentation technique in application to hardened cement paste. Cement and Concrete Research, 41(1):20-29, January 2011.

[9] G. Feng and A. H. W. Ngan. Effects of creep and thermal drift on modulus measurement using depth-sensing indentation. Journal of Materials Research, 17(03):660-668, January 2011.

[10] L.A. Galin. Contact problems in the theory of elasticity. Gostekhizdat, Moscow, 1953.

[11] Elias Ghossein and Martin Lévesque. A fully automated numerical tool for a comprehensive validation of homogenization models and its application to spherical particles reinforced composites. International Journal of Solids and Structures, 49(11-12):1387-1398, June 2012.

[12] Laurent Granger. Comportement différé du béton dans les enceintes de centrales nucléaires: analyse et modélisation. PhD thesis, Ecole Nationale des Ponts et Chaussées, 1995. 
[13] C Huet, P Acker, and J Baron. Fluage et autres effets rhéologiques du béton. In Le Béton Hydraulique, chapter 19, pages 355-364. Presses de l'Ecole Nationale des Ponts et Chaussées, 1982.

[14] Zhengwu Jiang, Zhenping Sun, and Peiming Wang. Autogenous relative humidity change and autogenous shrinkage of high-performance cement pastes. Cement and Concrete Research, 35(8):1539-1545, August 2005.

[15] Milan Jirasek and Svatopluk Dobrusky. Accuracy of Concrete Creep Predictions Based on Extrapolation of Short-Time Data. In Proceedings of the 5th international conference on reliable engineering computing, pages 197-207, 2012.

[16] Robert Le Roy. Déformations instantanées et différées des bétons à hautes performances. PhD thesis, 1996.

[17] J Marchand. Résistance et module des pâtes de ciment à hautes performances. Technical report, LCPC, Paris, 1992.

[18] A.S. Maxwell, M.A. Monclus, N.M. Jennett, and G Dean. Accelerated testing of creep in polymeric materials using nanoindentation. Polymer Testing, 30(4):366-371, June 2011.

[19] Mahalia Miller, Christopher Bobko, Matthieu Vandamme, and FranzJosef Ulm. Surface roughness criteria for cement paste nanoindentation. Cement and Concrete Research, 38(4):467-476, April 2008.

[20] P Mondal, S P Shah, and L Marks. A reliable technique to determine the local mechanical properties at the nanoscale for cementitious materials. Cement and Concrete Research, 37(10):1440-1444, October 2007. 
[21] Jií Němeček. Creep effects in nanoindentation of hydrated phases of cement pastes. Materials Characterization, 60(9):1028-1034, September 2009.

[22] W.C. Oliver and G.M. Pharr. An improved technique for determining hardness and elastic modulus using load and displacement sensing indentation experiments. Journal of Materials Research, 7(6):1564-1583, January 1992.

[23] M L Oyen and R F Cook. Load-displacement behavior during sharp indentation of viscous-elastic-plastic materials. Journal of Materials Research, 18(1):139-150, 2003.

[24] Ch Pichler and R Lackner. Identification of Logarithmic-Type Creep of Calcium-Silicate-Hydrates by Means of Nanoindentation. Strain, 45(1):17-25, February 2009.

[25] Warangkana Saengsoy, Toyoharu Nawa, and Pipat Termkhajornkit. Influence of relative humidity on compressive strength of fly ash cement paste. Journal of Structural and Construction Engineering, 73(631):1433-1441, 2008.

[26] J Salençon. Viscoélasticité. Presses de l'Ecole Nationale des Ponts et Chaussées, 1981.

[27] C Schuh and D.C Dunand. An overview of power-law creep in polycrystalline $\beta$-titanium. Scripta Materialia, 45(12):1415-1421, December 2001. 
[28] François Toutlemonde and Fabrice Le Maou. Protection des éprouvettes de béton vis-à-vis de la dessiccation -Le point sur quelques techniques de laboratoire. Bulletin des Laboratoires des Ponts et Chaussées, 203:105119, 1996.

[29] Franz-Josef Ulm, Fabrice Le Maou, and C Boulay. Creep and shrinkage coupling: new review of some evidence. Revue Française de Génie Civil, $3(3-4): 21-37,1999$.

[30] Franz-Josef Ulm, Matthieu Vandamme, Chris Bobko, Jose Alberto Ortega, Kuangshin Tai, and Christine Ortiz. Statistical indentation techniques for hydrated nanocomposites: concrete, bone, and shale. Journal of the American Ceramic Society, 90(9):2677-2692, September 2007.

[31] Matthieu Vandamme, Catherine A Tweedie, Georgios Constantinides, Franz-Josef Ulm, and Krystyn J. Van Vliet. Quantifying plasticityindependent creep compliance and relaxation of viscoelastoplastic materials under contact loading. Journal of Materials Research, 27(1):302312, October 2011.

[32] Matthieu Vandamme and Franz-Josef Ulm. Viscoelastic solutions for conical indentation. International Journal of Solids and Structures, 43(10):3142-3165, May 2006.

[33] Matthieu Vandamme and Franz-Josef Ulm. Nanogranular origin of concrete creep. Proceedings of the National Academy of Sciences, 106(26):10552-10557, 2009. 
[34] Matthieu Vandamme and Franz-Josef Ulm. Nanoindentation investigation of creep properties of calcium-silicate-hydrates. Cement and Concrete Research, 2013.

[35] Thai-Son Vu, Guillaume Ovarlez, and Xavier Chateau. Macroscopic behavior of bidisperse suspensions of noncolloidal particles in yield stress fluids. Journal of Rheology, 54:815-833, 2010.

[36] Wenzhong Zhu, John J. Hughes, Nenad Bicanic, and Chris J. Pearce. Nanoindentation mapping of mechanical properties of cement paste and natural rocks. Materials Characterization, 58(11-12):1189-1198, November 2007. 